\title{
EDITORIAL
}

\section{The rise and fall of endothelin receptor antagonists in congestive heart failure}

\author{
M.L. Handoko*,\#, F.S. de Man ${ }^{\#, \text { a }}$ and A. Vonk-Noordegraaf ${ }^{\#}$
}

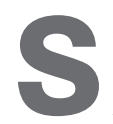
ince its discovery in 1988 [1], the role of endothelin in cardiovascular disease has been intensively studied. Activation of the endothelin system is considered part of the neurohormonal response in congestive heart failure. Endothelin is produced by vascular endothelial cells and has potent vasoconstrictor effects [2]. Elevated endothelin levels induce adverse cardiac remodelling and cause progressive aggravation of congestive heart failure by influencing loading conditions of the heart and by reducing coronary flow; endothelin also has direct (toxic) myocardial effects [2]. Several clinical studies have demonstrated that higher plasma levels of endothelin-1 correlates with the degree of haemodynamic and functional impairment, and worse prognosis in heart failure [3-6].

Motivated by these pathophysiological and epidemiological insights, drugs such as bosentan, an oral nonselective endothelin receptor antagonist, were developed that could interfere and reduce the effects of the endothelin system. Two independent studies, both using a post-infarction rat model of heart failure, reported beneficial long-term effects of bosentan on cardiac remodelling, haemodynamics and survival [7, 8]. A year later, short-term beneficial effects of bosentan were reported on haemodynamics, on top of triple treatment with diuretics, digoxin and angiotensin-converting enzyme inhibitors in patients with symptomatic heart failure [9]. Thus far, the therapeutic potential of endothelin receptor antagonists has seemed most promising.

Long-term studies in patients with symptomatic heart failure were conducted (Research on Endothelin Antagonism in Chronic Heart Failure (REACH) and Endothelin Antagonist Bosentan for Lowering Cardiac Events in Heart Failure (ENABLE)), but these trials were prematurely stopped, due to unexpected increases of adverse events, without improvements in clinical status [10-12]. Probably inspired by successful use of bosentan in patients with pulmonary arterial hypertension [13], a beneficial effect of bosentan was suggested for a subgroup of heart failure patients with secondary pulmonary hypertension. Unfortunately, a recent clinical trial demonstrated no effect for this subgroup either [14].

\footnotetext{
*Depts of Physiology and ${ }^{\#}$ Pulmonology, VU University Medical Center/Institute for Cardiovascular Research, Amsterdam, The Netherlands. 'University Paris-Sud, INSERM Unit 999, Centre Chirurgical Marie Lannelongue, Le Plessis-Robinson/Paris, France.

CORRESPONDENCE: M.L. Handoko, Dept of Physiology, VU University Medical Center, Van der Boechorststraat 7, 1081 BT Amsterdam, The Netherlands. E-mail: ml.handoko@vumc.nl
}

In the current issue of the European Respiratory Journal, JIANG et al. [15] studied the effects of bosentan in an animal model of pulmonary hypertension, secondary to heart failure. The strengths of this research are its integral approach, assessing both cardiac and pulmonary remodelling by functional and morphological parameters. Unfortunately, the authors did not confirm the presence of pulmonary hypertension at the start of treatment (i.e. by measuring right ventricular systolic pressures). Nevertheless, due to the severity of the myocardial infarction, it is probable that all animals had developed pulmonary hypertension at this timepoint. Interestingly, the same post-infarction rat model and comparable dosages of bosentan were used as in previous studies, which had demonstrated beneficial long-term effects $[7,8]$. In contrast, JIANG et al. [15] did not observe any effects on cardiac and pulmonary remodelling despite the use of sensitive measurements. Their findings, therefore, challenge the pathophysiological rationale for the use of endothelin receptor antagonists in heart failure with secondary pulmonary hypertension.

This study probably closes the discussion of the role of endothelin receptor antagonists in congestive heart failure: it is unfortunate to conclude that the endothelin receptor antagonists did not live up to their potential.

\section{STATEMENT OF INTEREST}

A statement of interest for A. Vonk-Noordegraaf can be found at www. erj.ersjournals.com/site/misc/statements.xhtml

\section{REFERENCES}

1 Yanagisawa M, Kurihara H, Kimura S, et al. A novel potent vasoconstrictor peptide produced by vascular endothelial cells. Nature 1988; 332: 411-415.

2 Nambi P, Clozel M, Feuerstein G. Endothelin and heart failure. Heart Fail Rev 2001; 6: 335-340.

3 Cody RJ, Haas GJ, Binkley PF, et al. Plasma endothelin correlates with the extent of pulmonary hypertension in patients with chronic congestive heart failure. Circulation 1992; 85: 504-509.

4 Pacher R, Bergler-Klein J, Globits S, et al. Plasma big endothelin-1 concentrations in congestive heart failure patients with or without systemic hypertension. Am J Cardiol 1993; 71: 1293-1299.

5 Omland T, Lie RT, Aakvaag A, et al. Plasma endothelin determination as a prognostic indicator of 1-year mortality after acute myocardial infarction. Circulation 1994; 89: 1573-1579.

6 Wei CM, Lerman A, Rodeheffer RJ, et al. Endothelin in human congestive heart failure. Circulation 1994; 89: 1580-1586.

7 Fraccarollo D, Hu K, Galuppo P, et al. Chronic endothelin receptor blockade attenuates progressive ventricular dilation and improves cardiac function in rats with myocardial infarction: possible 
involvement of myocardial endothelin system in ventricular remodeling. Circulation 1997; 96: 3963-3973.

8 Mulder P, Richard V, Derumeaux G, et al. Role of endogenous endothelin in chronic heart failure: effect of long-term treatment with an endothelin antagonist on survival, hemodynamics, and cardiac remodeling. Circulation 1997; 96: 1976-1982.

9 Sutsch G, Kiowski W, Yan XW, et al. Short-term oral endothelin-receptor antagonist therapy in conventionally treated patients with symptomatic severe chronic heart failure. Circulation 1998; 98: 2262-2268.

10 Packer M. Multicentre, double-blind, placebo-controlled study of long-term endothelin blockade with bosentan in chronic heart failure - results of the REACH-1 trial (abstract). Circulation 1998; 98: 1-3.

11 Mylona P, Cleland JG. Update of REACH-1 and MERIT-HF clinical trials in heart failure. Cardio.net editorial team. Eur J Heart Fail 1999; 1: 197-200.
12 Kalra PR, Moon JC, Coats AJ. Do results of the ENABLE (Endothelin Antagonist Bosentan for Lowering Cardiac Events in Heart Failure) study spell the end for non-selective endothelin antagonism in heart failure? Int J Cardiol 2002; 85: 195-197.

13 Rubin LJ, Badesch DB, Barst RJ, et al. Bosentan therapy for pulmonary arterial hypertension. $N$ Engl J Med 2002; 346: 896-903.

14 Kaluski E, Cotter G, Leitman M, et al. Clinical and hemodynamic effects of bosentan dose optimization in symptomatic heart failure patients with severe systolic dysfunction, associated with secondary pulmonary hypertension - a multi-center randomized study. Cardiology 2008; 109: 273-280.

15 Jiang $\mathrm{BH}$, Tardif J-C, Shi $\mathrm{Y}$, et al. Bosentan does not improve pulmonary hypertension and lung remodelling in heart failure. Eur Respir J 2011; 37: 578-586. 